\title{
American Journal of Pediatrics
}

\section{The Pentalogy of Cantrell: A Case Report}

\author{
Ni Nyoman Anik Cindi Yuliastini ${ }^{1, ~ *, ~ I ~ M a d e ~ K a r d a n a ~}{ }^{1}$, Kadek Deddy Ariyanta ${ }^{2}$ \\ ${ }^{1}$ Department of Child Health, Sanglah Hospital, Faculty of Medicine, Udayana University, Denpasar, Indonesia \\ ${ }^{2}$ Department of Surgery, Sanglah Hospital, Faculty of Medicine, Udayana University, Denpasar, Indonesia
}

\section{Email address:}

anikcindiy@gmail.com (Ni N. A. C. Yuliastini), made_kardana@yahoo.com (I M. Kardana), deddyariyanta@yahoo.com (K. D. Ariyanta)

${ }^{*}$ Corresponding author

\section{To cite this article:}

Ni Nyoman Anik Cindi Yuliastini, I Made Kardana, Kadek Deddy Ariyanta. The Pentalogy of Cantrell: A Case Report. American Journal of Pediatrics. Vol. 6, No. 3, 2020, pp. 268-272. doi: 10.11648/j.ajp.20200603.25

Received: June 17, 2020; Accepted: July 2, 2020; Published: July 13, 2020

\begin{abstract}
Pentalogy of Cantrell (PC) is a rare anomaly marked by the coexistence of omphalocele and ectopia cordis. Pentalogy of Cantrell comprises of the following five characteristics: midline, upper abdominal wall disorder (e.g. omphalocele, gastroschisis); defect of lower sternum (i.e. cleft sternum or absent sternum); anterior diaphragmatic defect (i.e. hypoplastic diaphragm, anterior diaphragmatic hernia); pericardial abnormality (e.g. ectopia cordis); congenital abnormalities of the heart (e.g. tetralogy of Fallot, ventricular septal defect, atrial septal defect). Toyama classified this syndrome into: class I - the occurrence of all 5 defects; class - II the occurrence of 4 defects with intracardiac and ventral abdominal wall abnormalities definitely present; class III - an incomplete expression of the disorders showing various combinations of defects, although sternal anomalies are definitely present. The incidence is estimated $5.5-7.9$ per 1 million live births with male predominance. PC can be diagnosed since antenatal through ultrasonography examination. Unfortunately, the mortality rate is quite high with minimal survival rate even with surgical reconstruction. We present a case of one-day old infant whom was referred from West Nusa Tenggara with suspicion of PC syndrome and neonatal pneumonia. The baby was born through cesarean section with mild asphyxia, birth weight was 3000 gram and body length was $48 \mathrm{~cm}$. There was no family and pregnancy risk factor. The multidisciplinary team consist of neonatologist, pediatric cardiologist and pediatric surgeon was teamed up to handle this case. There were some abnormalities in complete blood counts such as decreasing number of lymphocyte and neutrophil percentage and also increasing basophil percentage. Chest and abdominal X-ray showed a suspicion of pneumonia but this didn't align with our physical examination. Echocardiography showed the infant had congenital heart defects such as Taussig Bing anomaly, single atrium, mild valvular pulmonary stenosis, mild tricuspid regurgitation and mesocardia. Genetic testing and further radiologic examination other than plain X-ray were not done in this case. There was no further intervention for this patient other than regular echocardiography and antibiotic topical treatment.
\end{abstract}

Keywords: Pentalogy of Cantrell, Ectopia Cordis, Omphalocele

\section{Introduction}

Pentalogy of Cantrell (PC) is a rare anomaly and was first described in 1958 by James R Cantrell et al. The components of the PC are defined as external herniation of heart, pericardial diaphragmatic defect, lower sternal defect, anterior diaphragmatic defect, intracardiac defect and malrotation of heart [1]. The pathognomonic characteristic of this syndrome is the coexistence of omphalocele and ectopia cordis [2]. However only several cases of PC presented with those five classical findings, therefore Toyama classified PC into three subgroups based on the expression of symptoms
[3].

The incidence about $5.5-7.9$ per 1 million live births and male predominance with ratio $2.7: 1[4,5]$. This syndrome is caused by developmental failure between $14^{\text {th }}$ and $18^{\text {th }}$ day of embryonic life which involves inappropriate differentiation of lateral mesoderm segment [1]. The etiologic factor is unknown until now while familial occurrence of both isolated ectopia cordis and PC has been reported [6]. Based on these, $\mathrm{PC}$ is considered caused by multifactorial etiology.

Antenatally diagnosis is crucial to determine the severity of the disorder in order to discuss the adequate therapeutic management [7]. The treatment will depend on the type of 
ectopic cordis, the size of abdominal defect, concomitant defect and disorder $[2,1]$.

In addition, surgical plan can be made as stepwise or single operation depends on patient's clinical data, hemodynamic compatibility, thoracic cavity compatibility and type of the intracardiac defect. The primary objectives of surgical treatment are to cover the heart with tissue, place the heart into the thoracic cavity, repair the intracardiac defects and the sternal-thoracic reconstruction [2,9]. The prognosis of patient depends on the size of the abdominal wall defect, the type of ectopia cordis and the associated anomalies. Mortality rate was higher in infants with the complete form of PC and associated extracardiac anomalies, such as cleft lip with or without cleft plate together with encephalocele or patient with trisomy 18. Intracardiac abnormalities itself do not seem to influence prognosis but this is still doubtable [8].

\section{Case Report}

A male, one-day old baby was referred from West Nusa Tenggara district hospital to our emergency center in Sanglah Hospital in suspicion of PC syndrome with ectopia cordis, omphalocele and pneumonia. He was born on $40^{\text {th }}$ weeks of pregnancy through cesarean section with mild asphyxia; APGAR score was 6-8. Cesarean section was choosen because of premature rupture of membrane.

Birth weight was 3000 gram and body length was $48 \mathrm{~cm}$. There was no other abnormality found during inspection rather than ectopia cordis and omphalocele. He is the first son in the family and there was no family history with similar symptom. During pregnancy, mother routinely checked to midwife and denied consuming any medication other than supplement given by midwife.

The physical examination indicated that the patient was active and generally appeared to be in good condition. The vital signs such as pulse, respiration rate, body temperature and oxygen saturation were also normal. In addition we also heard systolic murmur through auscultation.

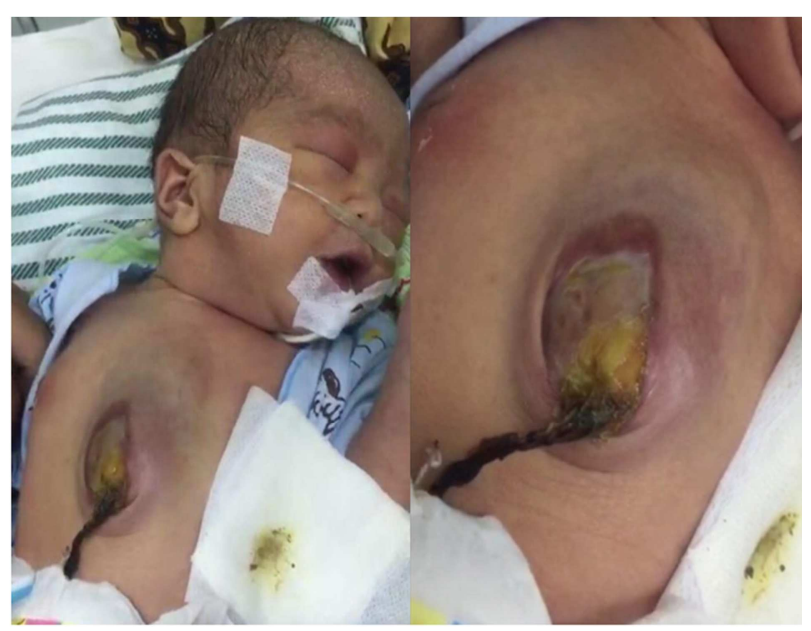

Figure 1. The clinical picture of the patient showed partial ectopia cordis and omphalocele. This picture was published with parental permission.
This patient was supervised by neonatologist, pediatric cardiologist and pediatric surgeon. Furthermore additional examination such as complete blood count, thorax-abdominal $\mathrm{X}$-ray and echocardiography were done to examine the baby's condition. The complete blood count showed decreasing number of lymphocyte and neutrophil percentage and also increasing basophil percentage which can be ignored. On the other hand, chest and abdominal X-ray from the previous hospital showed suspicion of pneumonia but this did not align with our physical examination result so we didn't treat him as pneumonia.

Echocardiography was performed by pediatric cardiologist and found some intracardiac defects such as Taussig Bing anomaly, single atrium, mild valvular pulmonary stenosis, mild tricuspid regurgitation, and mesocardia.

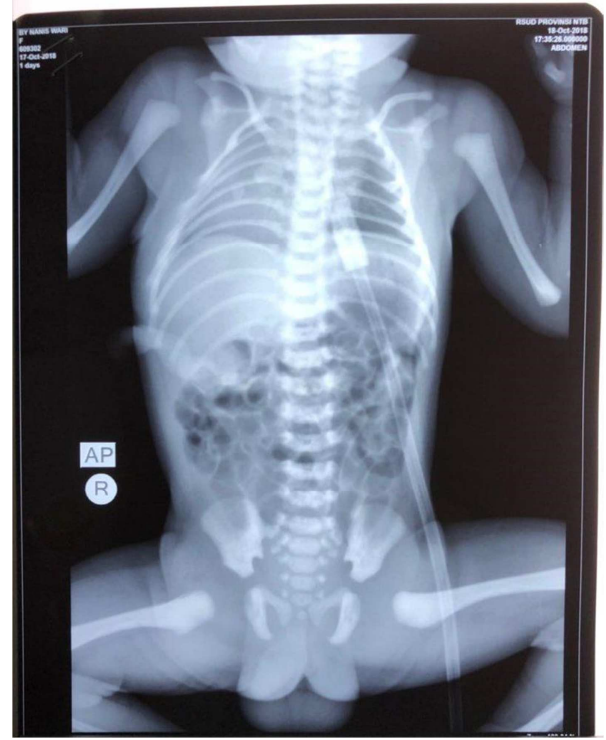

Figure 2. Plain X-ray from previous hospital stated pneumonia

All departments concluded that there wouldn't perform any further treatment other than conservative treatment for this patient. The parents were educated to perform monthly echocardiography in outpatient clinic and Nebacetin powder was prescribed for him. No genetic testing was performed.

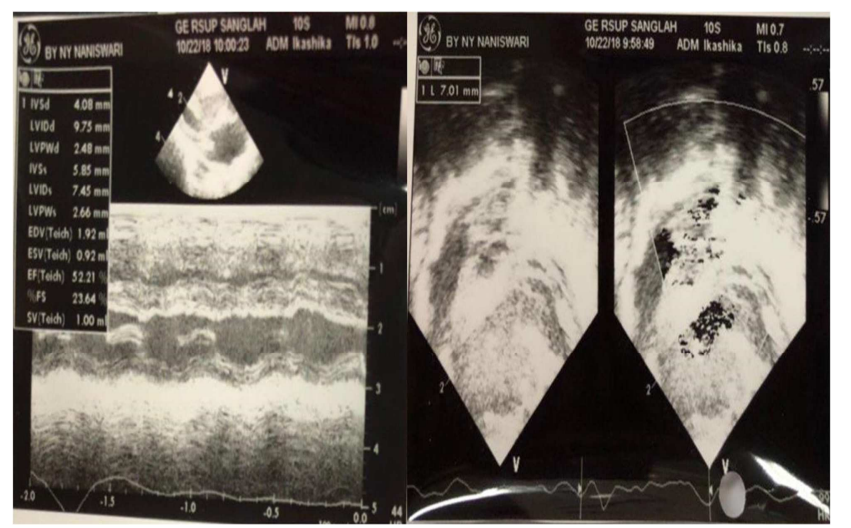

Figure 3. Echocardiography result showed some intracardiac problems. 


\section{Discussion}

The pentalogy of Cantrell comprises of five characteristics such as: midline, upper abdominal wall disorder (e.g. omphalocele, gastroschisis); defect of lower sternum (i.e. cleft sternum or absent sternum); anterior diaphragmatic defect (i.e. hypoplastic diaphragm, anterior diaphragmatic hernia); pericardial abnormality (e.g. ectopia cordis); congenital abnormalities of the heart (e.g. tetralogy of Fallot, ventricular septal defect, atrial septal defect) $[1,9]$.

Toyama classified this syndrome into: class I - the occurrence of all 5 defects; class - II the occurrence of 4 defects with intracardiac and ventral abdominal wall abnormalities definitely present; class III - an incomplete expression of the disorders showing various combinations of defects, although sternal anomalies are definitely present [3]. In our case there are omphalocele, ectopia cordis and intracardiac abnormalities so we categorized him as pentalogy of Cantrell class II [10].

During embryonic development; the sternum, abdominal wall, pericardium and part of the diaphragm arise from somatic mesoderm, while myocardium arises from splanchnic mesoderm [10]. The abnormal development of septum transversum can result into pericardial and diaphragmatic anomalies. Defects relating to the migration of mesodermal structures represent the possible cause of abdominal wall and sternum anomalies [6, 10]. While the specific pathogenesis of the disease has not yet been elucidated, it is known that the differentiation occurs between $14^{\text {th }}$ and $18^{\text {th }}$ day after conception. It has been suggested that, during that period, the lateral mesodermal fold failed to migrate toward the midline resulted in abdominal and sternal defects, while problems relating to the development of the septum transversum resulted in pericardial and anterior diaphragm defects $[10,11]$. It is believed that the ventricular diverticulum arises from the abnormal fusion of cardiac loop to the yolk sac during the embryonic development [10, 12]. The vast majority of patients with PC have intracardiac defects. The complicated cardiac anomaly plays significant role in the prognosis. There are many forms of intracardiac defects. The most common form is ventricular septal defect (VSD), followed by an atrial septal defect (ASD) [13]. As our patient also have an intracardiac defect so it fits with the majority of PC patients. He presented with Taussig Bing anomaly, single atrium, mild valvular pulmonary stenosis, mild tricuspid regurgitation, and mesocardia.

The most common form of sternal malformations is the absence of the lower third portion, bifid sternum, absence of xiphoid process and short sternum. Pericardial and diaphragmatic abnormalities are dominated by the absence of pericardium and the absence of the anterior part of the diaphragm. The absent pericardium establishes the differential diagnosis of PC with ectopia cordis [1].

Ectopia cordis is a typical feature of PC and defined as partial or complete displacement of the fetal heart outside the thoracic cavity. Studies report its prevalence about 7.9:1 million live birth [14] Ectopia cordis can be categorized into four types based on the heart location: cervical - the most uncommon (3\%); thoracic - the most common (60\%); abdominal (30\%); and thoracoabdominal (7\%) [15]. Heart originally develops in cephalic part of the embryo and reaches its final location by $16^{\text {th }}-17^{\text {th }}$ day of embryogenesis, whereas complete developmental fusion lead to the formation of the thoracic and abdominal cavities occurs by the $9^{\text {th }}$ week of embryonic life $[1,16]$. Incomplete fusion can cause a wide range of disorders, varying from isolated ectopia cordis to complete ventral evisceration [17]. Many theories have been proposed to explain the etiology of this condition such as the amniotic rupture theory that describes ectopia cordis with amniotic band, although isolated ectopia cordis may occur secondary to other etiological contributors such as exposure to intrauterine drugs [18]. In our case, the mother denied any drug intake during pregnancy other than supplementation given by midwife and there was no history of consanguinity.

The pentalogy of Cantrell may also be associated with various organ and system abnormalities [19]. The incidence is reported increased with the presence of trisomy 13 and 18[20, 21]. Mutation in the Porcupine homolog gene was reported in a patient with PC and focal dermal hypoplasia and in those with the limb-body wall complex syndrome $[22,23]$ Porcupine, an O-acyltransferase involved in the acylation of Wnt ligands, is located on the X chromosome, and its deletion in mice is known to cause focal dermal hypoplasia and developmental anomalies of it's body wall [24] However, it is unclear if a mutation in Porcupine also causes PC [25]. Most cases so far were described sporadic, but in some families, an X-linked pathway has been suggested and in some cases alterations in the region, Xq25-q26.1 had been found [7]. However, there is still no conclusive data available on the etiology and pathogenesis of PC. Unfortunately, we did not perform genetic testing for this patient.

Prenatal imaging studies are crucial for prenatal counseling and adequate postnatal therapeutic planning [25]. The diagnosis of PC may be established by fetal ultrasonography during the first trimester of the pregnancy as early as 10 weeks of pregnancy [26, 27]. Attempts should be made to exclude this syndrome in patients with omphalocele, diaphragmatic hernia and pericardial defect accompanied by pericardial effusion detected during prenatal assessment [26]. Amniocentesis might be performed because of its association with genetic disorder [27].

Fetal echocardiography and MRI will provide more detail assessments as well as more comprehensive examination of the cardiac structure, which is important for pediatrician and surgeon to provide care and treatment for the infant following delivery [26, 28]. Nowadays, three-dimensional sonography has been widely used and preferred by physicians for these patients [27]. While other study stated that 2D sonography with Doppler imaging is the choice for sonography assessment of abdominal wall defects during the first trimester. 3D sonography is a valuable tool for evaluation of fetuses with abdominal wall defects during the second and third trimesters but its not essential in the first trimester. 3D sonography can be used to help with parent counseling, 
because it provides images that are easily understood [29].

Ectopia cordis is not considered as indication for section cesarean in the literature and the patients are followed up under normal obstetric indications. It is reported that there wasn't any prognostic difference between normal delivery and cesarean section in patients with ectopia cordis. However, some authors highlight the significance of sterility for the postpartum surgery and prefer cesarean section [26]. Actually, in this case the mother had cesarean section because of premature rupture of membrane and the syndrome was not detected through antenatal care because of ultrasonography examination wasn't performed by midwife.

The treatment will depend on their type of EC, the size of the abdominal defect and the concomitant defects and disorders [21]. The surgical plan could be made as stepwise or a single operation procedure depend on the patient clinical data, hemodynamic compatibility, thoracic cavity compatibility and the type of intracardiac defect. The primary objectives of the surgical treatment are to cover the heart with tissue, place the heart into the thoracic cavity, repair the intracardiac defects and the sternal-thoracic reconstruction [30]. In this case, pediatric surgeon considered the patient only need conservative therapy and Nebacetin powder was given as topical treatment.

Cantrell's syndrome has poor prognosis. There is no consensus on the prognosis and some authors consider the type of intracardiac defect as the most important factor in determining the prognosis; whereas some author argues that the class of the syndrome determines the prognosis [7, 8, 31].

The mortality rate is quite high with survival rate less than $5 \%$ [32]. Even the very mild or incomplete form of PC has only less than $40 \%[3,33]$. However, Nichal et al reported a unique case which untreated patient of $\mathrm{PC}$ survived into sixth decade with omphalocele and bifid lower sternum and herniation of cardiac apex. He was managing the swelling with an abdominal wall harness for support [27].

Meanwhile a study by O'Gorman et al concluded that postoperative care of children with pentalogy of Cantrell after cardiac surgery is often complicated by prolonged need for ventilator support and multiple postoperative complications. Early surgical intervention does not reduce morbidity and mortality [33]. Even though PC has a high mortality rate, we hope our patient will survive and regular echocardiography was scheduled to monitor his condition.

\section{Conclusion}

Pentalogy of Cantrell is a rare syndrome with various combinations of defects but the pathognomonic characteristic of this syndrome is the coexistence of omphalocele and ectopia cordis. The exact etiology is still unknown until nowaday and considered as multifactorial. Many aspects affect the prognosis which is usually poor with minimal survival rate even after surgical intervention.

\section{Funding}

Nil.

\section{References}

[1] Cantrell, J. R., Haller, J. A., \& Ravitch, M. M. A syndrome of congenital defects involving wall, sternum, diaphragm, pericardium, and heart. Surg Gynecol Obstet. 1958: 602-14.

[2] Sarkar, P., Bastin, J., Katoch, D., \& Pal, A. Pentalogy of Cantrell: Diagnosis in the first trimester. J Obstet Gynaecol. 2005; 25 (8): 812-3.

[3] Toyama, W. M. Combined congenital defects of the anterior abdominal wall, sternum, diaphragm, pericardium, and heart: A case report and review of the syndrome. Pediatrics. 1972; $50(5) ; 778-92$.

[4] Khoury, M. J., Cordero, J. F., \& Rasmussen, S. Ectopia cordis, midline defects, and chromosomal abnormalities. Am J Med Genet. 1988; 30 (3); 811-7.

[5] Bittmann, S., Ulus, H., \& Springer, A. Combined pentalogy of cantrell with tetralogy of fallot, and gallbladder agenesis, and polysplenia: A case report. J Pediatr Surg. 2004; 39 (1): 107-9.

[6] Morales, J. M., Patel, S. G., Duff, J. A., Villareal, R. L., \& Simpson, J. W. Ectopia cordis and other midline defects. Ann Thorac Surg. 2000; 70 (1): 111-4.

[7] Gubler, D. F., Berger, T. M., Pelikan, S., \& Kohl, J. (2015, December). Pentalogy of cantrell. 1-13. Switzerland: Swiss Society of Neonatology. Retrieved from https://www.neonet.ch/files/9314/4239/1236/Cotm_December 2015.pdf.

[8] Von Hoorn, J. H., Moonen, R. M., Huysentruyt, C. J., van Heurn, L. W., Offermans, J. P., \& Mulder, A. L. Pentalogy of cantrell: Two patients and a review to determine prognostic factors for optimal approach. Eur J Pediatr. 2008; 167: 29-35.

[9] Mendaluk, T., Moscicka, A., Mrozinski, B., \& Szymankiewicz, M. The incomplete pentalogy of Cantrell - A case report. Pediatria Polska. 2015: 241-4.

[10] Isik, O., Akyuz, M., Ayik, M. F., Koroglu, O. A., Ozyurek, A. R., \& Atay, Y. Pentalogy of cantrell. J Clin Anal Med. 2014; 5 (3): 427-9.

[11] Haynor, D. R., Shuman, W. P., \& Brewer, D. K. Imaging of fetal ectopia cordis: Roles of sonography and computed tomography. J Ultrasound Med. 1984; 3 (1), 25-7.

[12] Nanda, S., Nanda, S., Agarwal, U., Sen, J., \& Sangwan, K. Cantrell syndrome - Report of two cases with one atypical variant. Arch Gynecol Obstet. 2003; 268 (2): 331-332.

[13] Bryke, C. R., \& Breg, W. R. Pentalogy of cantrell. In M. L. Buyse (Ed.), Birth defects encyclopedia. Blackwell Scientific Publications. 1990; 42: 1375-6.

[14] Pamidi, N., Vollala, V. R., Nayak, S., \& Bhat, S. Case report Ectopia cordis and amniotic band syndrome. Arch Med Sci. 2008; 4: 208-11.

[15] Celik, Y., Hallioglu, O., Basut, N., Demetgul, H., \& Esin Kibar, A. A rare case of cardiac anomaly: Prenatally diagnosed ectopia cordis. Turk Pediatri Arsivi. 2015; 50: 129-131. 
[16] Shad, J., Budhwani, K., \& Biswas, R. Thoracic ectopia cordis. BMJ Case Rep. 2012: 1-4.

[17] Pius, S., Abubakar Ibrahim, H., Bello, M., \& Bashir Tahir, M. Complete ectopia cordis: A case report and literature review. Case Rep Pediatr. 2017.

[18] Jaffee, O. C., \& Jaffee, A. L. Ectopia cordis in the chick embryo heart: An experimental study. Teratology. 1990; 41: 737-42.

[19] Carmi, R., \& Boughman, J. A. Pentalogy of cantrell and associated midline anomalies: A possible ventral midline developmental field. Am J Med Genet. 1992; 42 (1): 90-95.

[20] Ghidini, A., Sirtori, M., Romero, R., \& Hobbins, J. C. Prenatal diagnosis of pentalogy of cantrell. J Ultrasound Med. 1988; 7 (10): 567-572.

[21] Baker, M. E., Rosenberg, E. R., Trofatter, K. F., Imber, M. J., \& Bowie, J. D. The utero findings in twins pentalogy of cantrell. J Ultrasound Med. 1984; 3 (11): 525-527.

[22] Smigiel, R., Jakubiak, A., Lombardi, M. P., Jaworski, W., Slezak, R., Patkowski, D., et al. Co-occurrence of severe Goltz-Gorlin syndrome and pentalogy of cantrell - Case report and review of the literature. Am J Med Genet A. 2011; 155 (5): 1102-5.

[23] Mass, S. M., Lombardi, M. P., van Essen, A. J., Wakeling, E. L., Castle, B., Temple, I. K., et al. Phenotype and genotype in 17 patients with Goltz-Gorlin syndrome. J Med Genet. 2009; 46 (10): 716-20.

[24] Barrot, J. J., Cash, G. M., Smith, A. P., Barrow, J. R., \& Murtaugh, L. C. Deletion of mouse Porcn blocks Wnt ligand secretion and reveals and ectodermal etiology of human focal dermal hypoplasia/Goltz syndrome. Proc Natl Acad Sci USA. 2011; 108: 12752-7.
[25] Marginean, C., Marginean, C. O., Gozar, L., Melit, L. E., Suciu, H., Gozar, H., et al. Cantrell syndrome - A rare complex congenital anomaly: A case report and literature review. Frontier in Pediatrics. 2018; 6: 2-6.

[26] McMahon, C. J., Taylor, M. D., Cassady, C. I., Olutoye, O. O., $\&$ Bezold, L. I.. Diagnosis of pentalogy of cantrell in the fetus using magnetic resonance imaging and ultrasound. Pediatr Cardiol. 2007; 28 (3): 172-175.

[27] Nischal, N., Arya, S., Puri, S. K., \& Trehan, V. K. Untreated patient of pentalogy of cantrell surviving into the sixth decade: A unique case report. IHJ Cardiovascular Case Reports. 2018.

[28] Doganay, S., Kantarci, M., \& Tanriverdi, E. C. Pentalogy of cantrell with craniorachischisis: MRI and ultrasonography findings. Ultraschall Med. 200829 (5): 278-80.

[29] Peixoto-Filho FM., Carneiro do Cima L., Nakamura-Pereira M. Prenatal Diagnosis of Pentalogy of Cantrell in the First Trimester: Is 3-Dimensional Sonography Needed?". J Clin Ultrasound. 2009; 37: 112-4.

[30] Zhang, X., XIng, Q., Sun, J., Huo, X., Kuang, M., \& Zhang, G. Surgical treatment and outcomes of pentalogy of cantrell in eight patients. J Pediatr Surg. 2014; 49 (8): 1335-40.

[31] Fernandez, I. S., Lopez, A., Vila, J. J., \& Lluna, J. M. Cantrell's pentalogy: Report of four cases and their management. Pediatr Surg Int, 12 (5), 428-431.

[32] Halbertsma, F. J., van, O. A., \& Staak, F. (2002). Cardiac diverticulum and omphalocele: Cantrell's pentalogy or syndrome. Cardiol Young. 1997; 12 (1): 71-4.

[33] O'Gorman, C. S., Tortoriello, T. A., \& McMahon, C. J. Outcome of children with pentalogy of cantrell following cardiac surgery. Pediatr Cardiol. 2009; 30 (4): 426-30. 